\title{
Phenylalanine Absorption and Metabolism in Parkinsonian Patients
}

\author{
ANN-KATHRINE GRANERUS， RUDOLF JAGENBURG， STIG RÖDJER， ALVAR SVANBORG
}

British Medical fournal, 1971, 4, 262-264

\section{Summary}

Oral and intravenous L-phenylalanine loading tests were performed in 13 Parkinsonian patients and in 12 control subjects matched for age and weight. The results showed a normal intestinal absorption and a normal elimination from plasma of phenylalanine in the Parkinsonian patients.

\section{Introduction}

In Parkinsonian patients there is a lowered content of dopamine in the neostriatum and in the substantia nigra (Hornykiewicz, 1963). Cotzias et al. (1967) postulated that this is due to defective hydroxylation of tyrosine to 3, 4-dihydroxyphenylalanine. A decreased absorption of phenylalanine and a deficient tyrosine hydroxylation in Parkinsonian patients was proposed to explain the findings after oral L-phenylalanine tolerance tests but an increased rate of metabolism of tyrosine and phenylalanine could not be excluded (Braham et al., 1969). The aim of the present investigation was to study the absorption and turnover of phenylalanine in Parkinsonian patients by means of oral and intravenous L-phenylalanine loadings.

\section{Subjects}

The study included 13 Parkinsonian patients $(6$ men and 7 women). Their ages ranged from 50 to 77 (mean 63) years and body weight from 46 to 69 (mean 59) kg. Anticholinergic therapy was withdrawn on the days of investigation. Two patients, one man and one woman, were also on treatment with vitamin $B_{12}$ because of pernicious anaemia.

The control group consisted of 12 subjects. Their ages ranged from 51 to 81 (mean 63) years and body weight from 45 to 69 (mean 60) kg. Ten of the control subjects were in hospital because of earlier cerebral vascular disease, the remaining two were a woman with valvular heart disease without congestive failure and an apparently healthy man of the hospital staff.

None of the subjects suffered from endocrine disorders or from diseases of the gastrointestinal tract. Liver function tests (bilirubin, thymol, alkaline phosphatase, and transaminases) were normal in all subjects except in one Parkinsonian patient with fractures, who had a moderate increase in the serum alkaline phosphatase activity. In all cases the food intake was ordinary. The physical activity was comparable in both groups. None of the subjects were bedridden.

\footnotetext{
Department of Clinical Chemistry, Sahlgren's Hospital, University of Gothenburg, Sweden

R. JAGENBURG, M.D., Assistant Professor

S. RODJER, M.D., Resident

Department of Geriatrics I, Vasa Hospital, University of Gothenburg, Sweden

A. SVANBORG, M.D., Head of Department

A.-K. GRANERUS, M.D., Resident
}

\begin{abstract}
Methods
Intravenous L-Phenylalanine Loading.-L-Phenylalanine 300 $\mu \mathrm{mol} / \mathrm{kg}$ body weight given as a $2.5 \%$ solution (kindly supplied by AB Astra, Södertälje, Sweden) was injected into a cubital vein in less than three minutes, in some subjects together with $0.4 \mathrm{mCi}$ of tritium-labelled water (THO). Blood sampling was performed before the injection and every 5-10 minutes for the following 150 minutes. No untoward effects were noticed during the loading.

Oral L-Phenylalanine Loading.-The day after the intravenous loading the patients were given $100 \mathrm{mg}(606 \mu \mathrm{mol})$ of $\mathrm{L}$-phenylalanine per $\mathrm{kg}$ body weight. The amino-acid was dissolved in $300 \mathrm{ml}$ of coffee. Blood was taken before and 30, 45, $60,90,120$, and 180 minutes after the L-phenylalanine intake.
\end{abstract}

All loadings were performed in the morning after an overnight fast. Venous blood samples were drawn into heparinized tubes from an indwelling catheter. The blood samples were immediately centrifuged. The separated plasma was kept frozen until analysis.

Chemical Methods.-Phenylalanine and tyrosine were measured fluorometrically (McCaman and Robins, 1962; Waalkes and Udenfriend, 1957). These methods were standardized with plasma samples with known amino-acid concentrations (phenylalanine varying from 50 to $1,600 \mu \mathrm{mol} / 1$., tyrosine from 50 to $500 \mu \mathrm{mol} / 1$.) as determined by ion-exchange chromatography (Spackman et al., 1958). This later method was also used for urinary analysis. Tritium was analyzed in a Packard Tri-Carb liquid scintillation spectrophotometer. The plasma water was obtained by vacuum sublimation (Vaughan and Boling, 1961).

Calculations.-The plasma phenylalanine disappearance curve after the intravenous L-phenylalanine injection was considered as biexponential (Fig. 1). The rate constants and distribution coefficients were calculated, assuming a two-compartment model (Shore and Callahan, 1963; Atkins, 1969). The rate

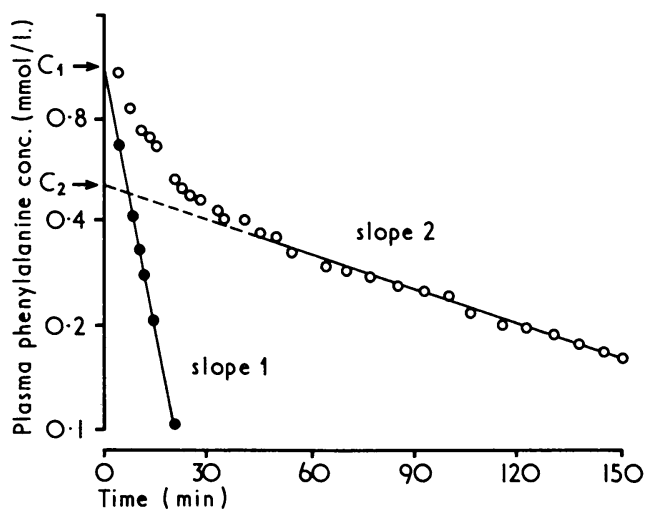

FIG. 1-Plasma phenylalanine disappearance curve (observed value minus fasting value) after intravenous L-phenylalanine injection ( $O-O$ ) in patient 3. The regression of slope 2 is subtracted from the plasma curve to give slope 1. (

constant $\left(k_{2}\right)$ of slope 2 (Fig. 1) was calculated from the regression line in the interval 50-150 minutes after the injection. From the theoretical concentration at zero time $\left(c_{2}\right)$ the apparent distribution coefficient $\mathrm{D} / \mathrm{c}_{2}$ was calculated, where $\mathrm{D}$ is 
Rate Constants $\left(k_{1}, k_{2}\right)$, Half-times ( $\left.1 / 2\right)$, and Distribution Coefficients $\left(D / c_{1}+c_{2}, D / c_{2}\right)$ Determined after Intravenous Injection of 1 -phenylalanine in Control Subjects and Parkinsonian Patients

\begin{tabular}{|c|c|c|c|c|c|c|c|c|c|c|}
\hline & \multirow{2}{*}{\multicolumn{2}{|c|}{ Subject }} & \multirow{2}{*}{ Sex } & \multicolumn{3}{|c|}{ Slope 1} & \multicolumn{3}{|c|}{ Slope 2} & \multirow{2}{*}{$\begin{array}{c}\text { Total Body Water* } \\
(1 . / \mathbf{k g})\end{array}$} \\
\hline & & & & $\left(\begin{array}{c}\mathbf{k}_{1} \\
\left(\mathbf{m i n}^{-1}\right)\end{array}\right.$ & $\begin{array}{l}t 1 / 2 \\
(\min )\end{array}$ & $\begin{array}{c}\mathrm{D} / \mathrm{c}_{1} \times \mathrm{c}_{2} \\
(1 . / \mathbf{k g})\end{array}$ & $\left(\min ^{-1} k_{2} \times 10^{2}\right)$ & $\begin{array}{l}t 1 / 2 \\
(\min )\end{array}$ & $\begin{array}{c}\mathrm{D} / \mathrm{c}_{\mathbf{2}} \\
(\mathbf{1} . / \mathbf{k g})\end{array}$ & \\
\hline \multicolumn{11}{|c|}{ Control Subjects } \\
\hline $\begin{array}{r}1 \\
2 \\
3 \\
4 \\
5 \\
6 \\
7 \\
8 \\
9 \\
10 \\
11 \\
12 \\
\end{array}$ & 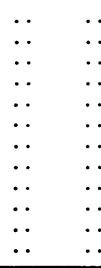 & 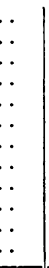 & $\begin{array}{l}\text { M. } \\
\text { F. } \\
\text { F. } \\
\text { M. } \\
\text { M. } \\
\text { F. } \\
\text { M. } \\
\text { F. } \\
\text { M. } \\
\text { M. } \\
\text { F. } \\
\text { F. }\end{array}$ & $\begin{array}{l}0.08 \\
0.10 \\
0.09 \\
0.12 \\
0.08 \\
0.09 \\
0.08 \\
0.17 \\
0.09 \\
0.08 \\
0.09 \\
0.10 \\
\end{array}$ & $\begin{array}{l}9 \\
7 \\
8 \\
6 \\
9 \\
8 \\
9 \\
4 \\
8 \\
9 \\
8 \\
7 \\
\end{array}$ & $\begin{array}{l}0.29 \\
0.15 \\
0.26 \\
0.22 \\
0.16 \\
0.22 \\
0.21 \\
0.20 \\
0.19 \\
0.15 \\
0.26 \\
0.17 \\
\end{array}$ & $\begin{array}{l}0.71 \\
0.85 \\
0.74 \\
0.78 \\
1.01 \\
0.94 \\
1.04 \\
0.97 \\
0.88 \\
0.85 \\
0.81 \\
0.88 \\
\end{array}$ & $\begin{array}{l}97 \\
81 \\
94 \\
88 \\
68 \\
73 \\
67 \\
72 \\
79 \\
81 \\
86 \\
79 \\
\end{array}$ & $\begin{array}{l}0.93 \\
0.47 \\
0.44 \\
0.54 \\
0.46 \\
0.77 \\
0.59 \\
0.56 \\
0.65 \\
0.65 \\
0.45 \\
0.58 \\
\end{array}$ & $\begin{array}{l}0.55(0.61) \\
0.46 \\
0.45 \\
0.51 \\
0.53(0.55) \\
0.48 \\
0.56 \\
0.48(0.48) \\
0.59(0.62) \\
0.53(0.55) \\
0.48(0.54) \\
0.49 \\
\end{array}$ \\
\hline $\begin{array}{l}\text { Mean } \\
\text { S.D. } \\
\end{array}$ & . & $\because$ & & $\begin{array}{l}0.098 \\
0.026 \\
\end{array}$ & $\begin{array}{l}7.7 \\
1.5 \\
\end{array}$ & $\begin{array}{l}0.21 \\
0.05 \\
\end{array}$ & $\begin{array}{l}0.87 \\
0.10 \\
\end{array}$ & $\begin{array}{l}80 \\
10 \\
\end{array}$ & $\begin{array}{l}0.59 \\
0.15 \\
\end{array}$ & \\
\hline \multicolumn{11}{|c|}{ Parkinsonian Patients } \\
\hline $\begin{array}{r}1 \\
2 \\
3 \\
4 \\
5 \\
6 \\
7 \\
8 \\
9 \\
10 \\
11 \\
12 \\
13 \\
\end{array}$ & $\begin{array}{l}. \\
\therefore \\
\therefore \\
\therefore \\
\therefore \\
\therefore \\
\therefore \\
\therefore \\
\therefore \\
\therefore \\
\end{array}$ & 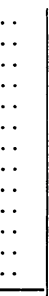 & $\begin{array}{l}\text { F. } \\
\text { F. } \\
\text { F. } \\
\text { M. } \\
\text { M. } \\
\text { M. } \\
\text { F. } \\
\text { M. } \\
\text { F. } \\
\text { M. } \\
\text { M. } \\
\text { F. } \\
\text { F. }\end{array}$ & $\begin{array}{l}0.08 \\
0.07 \\
0.12 \\
0.10 \\
0.13 \\
0.12 \\
0.11 \\
0.10 \\
0.09 \\
0.08 \\
0.10 \\
0.08 \\
0.09 \\
\end{array}$ & $\begin{array}{r}9 \\
10 \\
6 \\
7 \\
5 \\
6 \\
6 \\
7 \\
8 \\
9 \\
7 \\
9 \\
8 \\
\end{array}$ & $\begin{array}{l}0.24 \\
0.22 \\
0.21 \\
0.22 \\
0.19 \\
0.14 \\
0.23 \\
0.25 \\
0 \cdot 16 \\
0.19 \\
0.18 \\
0.24 \\
0.18 \\
\end{array}$ & $\begin{array}{l}1.26 \\
0.74 \\
0.76 \\
0.90 \\
1.04 \\
0.92 \\
0.97 \\
0.99 \\
1.01 \\
1.04 \\
0.74 \\
1.20 \\
0.94 \\
\end{array}$ & $\begin{array}{l}55 \\
94 \\
91 \\
77 \\
67 \\
75 \\
72 \\
70 \\
68 \\
67 \\
94 \\
58 \\
73 \\
\end{array}$ & $\begin{array}{l}0.82 \\
0.53 \\
0.74 \\
0.96 \\
0.60 \\
0.61 \\
0.64 \\
0.88 \\
0.56 \\
0.72 \\
0.64 \\
0.69 \\
0.43 \\
\end{array}$ & $\begin{array}{l}0.50(0.48) \\
0.44 \\
0.46(0.45) \\
0.55 \\
0.57 \\
0.54(0.54) \\
0.47 \\
0.56 \\
0.44 \\
0.49(0.52) \\
0.56(0.57) \\
0.50(0.52) \\
0.47 \\
\end{array}$ \\
\hline $\begin{array}{l}\text { Mean } \\
\text { S.D. }\end{array}$ & . & $\because$ & & $\begin{array}{l}0.098 \\
0.018\end{array}$ & $\begin{array}{l}7.5 \\
1.5\end{array}$ & $\begin{array}{l}0.20 \\
0.03\end{array}$ & $\begin{array}{l}0.96 \\
0.16\end{array}$ & $\begin{array}{l}74 \\
12\end{array}$ & $\begin{array}{l}0.68 \\
0.15\end{array}$ & \\
\hline
\end{tabular}

*Calculated from the formulas given by Moore et al. (1963). The figures in parentheses are experimentally determined.

the phenylalanine dose in $\mu \mathrm{mol} / \mathrm{kg}$ body weight. The rate constant $\left(k_{1}\right)$ for the disappearance of phenylalanine during the initial phase (slope 1) was calculated in the interval 5-25 minutes according to conventional technique (Atkins, 1969). By adding the theoretical concentrations of slopes 1 and 2 at zero time the initial distribution coefficient $\left(D / c_{1}+c_{2}\right)$ was determined. The half-times ( $t / 2)$ for the two slopes were calculated from the formula $t 1 / 2=\frac{0.693}{k}$. Total body water was determined from the formulas given by Moore et al. (1963) and from the distribution volume of THO. Theoretical concentration of THO at zero time was calculated from the concentrations at 90,120 , and 180 minutes, assuming a straight line.

\section{Results}

In the Parkinsonian patients the fasting plasma level (mean \pm S.D.) of phenylalanine was $60 \pm 14 \mu \mathrm{mol} / 1$. (controls $59 \pm 14 \mu \mathrm{mol} / 1$.) and of tyrosine $59 \pm 13 \mu \mathrm{mol} / 1$. (controls $67 \pm 20 \mu \mathrm{mol} / 1$.).

Intravenous $L$-Phenylalanine Loading. - The rate constants $\mathrm{k}_{1}$ and $k_{2}$ and the distribution coefficients $D / c_{1}+c_{2}$ and $D / c_{2}$ did not differ significantly in the two groups (Fig. 2, Table). The ratio between the apparent distribution volume of phenylalanine $\left(D / c_{2}\right)$ and the total body water ranged from 0.84 to 1.39 in 19 of the 25 subjects (mean 1.11). In six subjects (four Parkinsonian patients and two controls) values above 1.57 (maximum 1.75) were observed. The mean plasma tyrosine concentration increased from 59 to $111 \pm 23 \mu \mathrm{mol} / 1$. at 60 minutes in the Parkinsonian patients and from 67 to $96 \pm 16$ $\mu \mathrm{mol} / 1$. in the controls. The maximum concentration was reached within 60 minutes after the injection and then slowly decreased during the observation period. At 150 minutes the plasma tyrosine value was $96 \pm 24 \mu \mathrm{mol} / 1$. in the Parkinsonian and $90 \pm 15 \mu \mathrm{mol} / 1$. in the controls. The increase in the plasma tyrosine levels was thus equal in both groups. The urinary loss of phenylalanine during the observation period was in all subjects less than $1 \%$ of the injected dose.

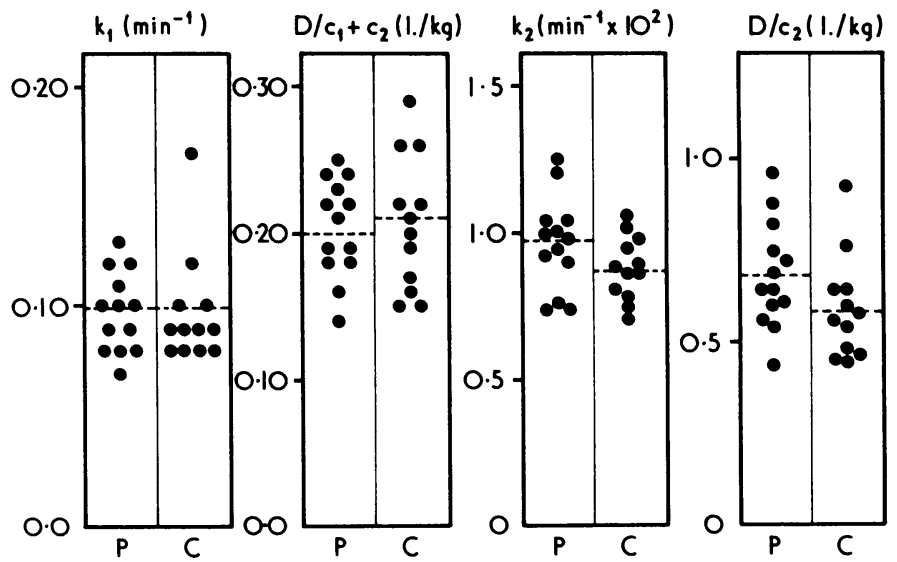

FIG. 2-Rate constants and the distribution coefficients of intravenously injected L-phenylalanine. Mean values are indicated by broken lines. $\mathbf{P}=$ Parkinsonian patients. $\mathbf{C}=$ Control patients.

Oral L-Phenylalanine Loading.-The plasma phenylalanine concentration increased rapidly to a peak value after $\mathbf{4 5}$ minutes (Fig. 3) and there was no significant difference between the two groups in the concentration at any of the observation times (Fig. 3). The increase in the tyrosine level was the same in both groups. In the two patients with pernicious anaemia the plasma phenylalanine curves were similar to those of the other subjects.

\section{Discussion}

The fasting plasma levels of phenylalanine and tyrosine in the Parkinsonian patients did not differ from the levels in the controls, which is in agreement with earlier reports (Van Woert, 1971; Hare et al., 1971). The plasma phenylalanine concentration after oral L-phenylalanine loading is determined both by the absorption from the intestine and by the disappearance from plasma. As shown from the intravenous injection 


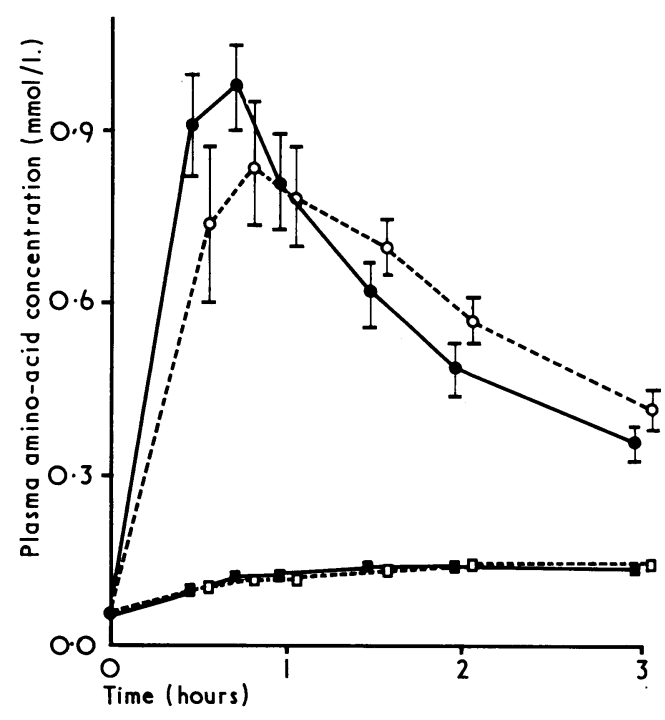

FIG. 3-Plasma phenylalanine and tyrosine concentration after oral Lphenylalanine loading. Mean values \pm S.E. are indicated. Parkinsonian patients: phenylalanine - Control patients: phenylalanine $O-O$, tyrosine $\square \stackrel{-}{\square}$.

the disappearance rate of phenylalanine from plasma is normal in Parkinsonian patients. The calculations of the disappearance rates were done, assuming a two-compartment model. The size of the initial distribution volume of phenylalanine was similar to the size of the extracellular volume (Moore et al., 1963). This phase mainly reflects distribution of phenylalanine to the intracellular compartment but also to a certain degree metabolism of the amino-acid as judged from the plasma tyrosine increase during the first hour. The second slope mainly reflects the hydroxylation of phenylalanine to tyrosine. The rate constant of this slope was similar in the Parkinsonian patients and in the controls and was in agreement with values observed in younger subjects (Bremer and Neumann, 1966; Woolf et al., 1967).

The increase in the plasma phenylalanine concentration after the oral loading did not indicate a defective phenylalanine absorption in the Parkinsonian patients. In fact there was a tendency to a more rapid increase than in the controls. The results obtained by Braham et al. (1969) could thus not be confirmed. In the study of Van Woert (1971) no difference was observed in the absorption of phenylalanine between Parkinsonian patients and controls, but the plasma phenylalanine curves differed markedly from those obtained in the present study. In the study of Van Woert (1971) the peak value was reached two hours after the phenylalanine intake, whereas in our study the maximum value was obtained after 45 minutes (Fig. 4). The cause of this discrepancy seems to be due to the fact that in the present study the phenylalanine was administered as a solution whereas Van Woert gave it as a suspension. When the amino-acid is not dissolved the plasma phenylalanine curve poorly reflects the absorption capacity of the intestine as the absorption will be influenced also by the rate of dissolution of the amino-acid in the gut.

In most of the subjects, Parkinsonian patients as well as controls, the apparent distribution volume of phenylalanine was similar to or somewhat larger than the total body water. In four of the Parkinsonian patients (two men and two women) and in

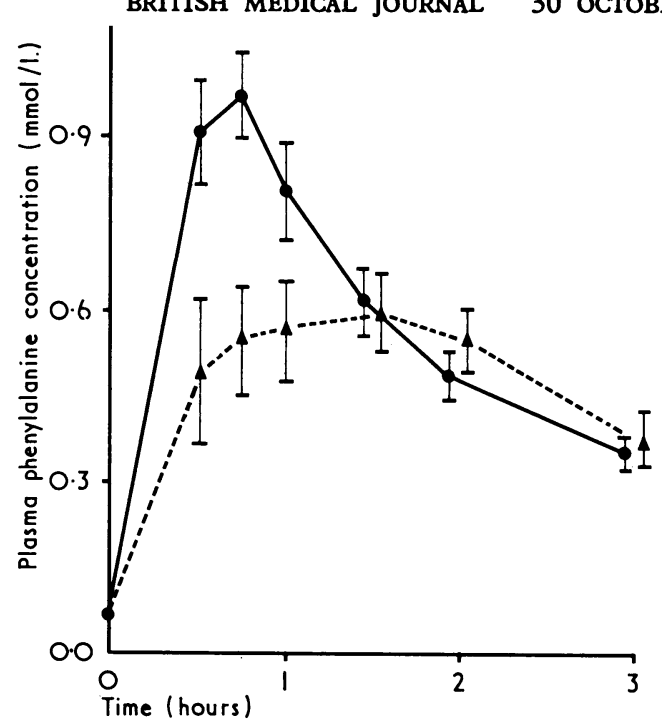

FIG. 4-Plasma phenylalanine concentration after oral L-phenylalanine loading in Parkinsonian patients. Mean values \pm S.E. are indicated. Iphenylalanine given as a solution (same as in Fig. 3), L-phenylalanine given as a suspension $\Delta-\Delta$ (unpublished results, $n=5$ ).

two of the controls (one man and one woman), however, the phenylalanine distribution volume was considerably larger than the volume of the total body water. These subjects did not obviously deviate from the other subjects so far as muscle mass, body weight, and nutritional condition are concerned. Eight of the Parkinsonian patients were reinvestigated after about six weeks of levodopa treatment (Granerus et al., 1971) and the phenylalanine distribution volume obtained at that time was in all patients in good agreement with that obtained at the first investigation. The reason for the large phenylalanine distribution volume in relation to total body water in some of the subjects cannot be explained. The sex difference observed by Woolf et al. (1967) in the phenylalanine distribution volume was not seen in our cases.

\section{References}

Atkins, G. L. (1969). Multicompartment Models for Biological Systems. London, Methuen.

Braham, J., et al. (1969). British Medical fournal, 2, 552.

Bremer, H. J., and Neumann, W. (1966). Nature, 209, 1148.

Cotzias, G. C., Van Woert, M. H., and Schiffer, L. M. (1967). New England Fournal of Medicine, 276, 374.

Granerus, A.-K., Jagenburg, R., Rödjer, S., and Svanborg, A. (1971). Proceedings of the Society for Experimental Biology and Medicine, 137, 942.

Hare, T. A., Vanna, S., Beasly, B., Chambers, R., and Vogel, W. H. (1971). fournal of Laboratory and Clinical Medicine, 77, 319.

Journal of Laboratory and Clinical Medicine, 77, 319.
Hornykiewicz, $\mathbf{O}$. (1963). Wiener klinische Wochenschrift, 75, 309. Hornykiewicz, O. (1963). Wiener klinische Wochenschrift, 75, 309.

Moore, F. D., et al. (1963). The Body Cell Mass and Its Supporting Environment. Philadelphia, Saunders.

Shore, M. L., and Callahan, R. (1963). Annals of the New York Academy of Sciences, 108, 147.

Spackman, D. H., Stein, W. H., and Moore, S. (1958). Analytical Chemistry, 30, 1190 .

Van Woert, H. M. (1971). Clinical Pharmacology and Therapeutics, 12, 368.

Vaughan, B. E., and Boling, E. A. (1961). Fournal of Laboratory and Clinical Medicine, 57, 159.

Waalkes, T. P., and Udenfriend, S. (1957). Fournal of Laboratory and Clinical Medicine, 50, 733.

Woolf, L. I., Cranston, W. I., and Goodwin, B. L. (1967). Nature, 213, 882. 